\title{
Editorial: Low dose fluorescein angiography
}

On naked eye inspection the blood inside vessels does not look as though it is actually moving. Even the very word 'vessel' describes a container meant to hold static fluid, while the word 'vein' can mean a coloured streak such as one sees in marble or geological strata of various colours of rock or minerals.

The speedy flow of the circulation is belied by the perfectly stationary appearance of the blood to an outside observer in, say, a vein on the back of one's hand or in those little red threads one can see in the whites of one's eyes more easily some mornings than others. Twenty-five years ago Novotny and Alvis gave the first demonstration in the retina of the speed and urgency of the circulation of the blood, a phenomenon which most of us had never previously witnessed except in an attenuated form in biology classes in the web of the frog's foot.

Fluorescein angiography of the retina has become an important part of ophthalmology and has demonstrated new pathological mechanisms, given new opportunities for diagnosis, and provided guidance for treatment in the major types of retinal disease. Its success has depended on many factors, one of the most important of which is the impermeability of normal retinal vessels to the fluorescein molecule, allowing a view of the retinal circulation in detail provided the vessel walls are all normal. With other tissues, however, we are not so lucky, as fluorescein escapes from normal connective tissue capillaries. Hence fluorescein angiography of tissues other than the retina has always been more difficult owing to blurring and fogging of the view by early 'leakage.'

Meyer and Watson in a paper in this issue describe an ingenious way of improving the quality of fluorescein pictures of the conjunctiva and episclera. They have discovered that if a small dose of fluorescein is used most of it becomes ionically bound to circulating albumin, and this effectively increases the size of the molecules, thus minimising 'leakage.' Photography with sensitive film (to allow for the small quantity of fluorescein in the circulation) then gives pictures of better quality than has been possible hitherto.

Such a device would probably minimise leakage even in pathological vessels so that the technique might be counterproductive in the study of disease, but it comes into its own in the study of normal anatomy, as the present paper shows.

To workers intent on unravelling the mysteries of the circulation in the anterior segment the old familiar diagram of the circulation after Leber must have seemed an inadequate description of the anatomy and flow pathways. The circulation as described by Meyer and Watson seems quite complicated and subject to individual and even intraindividual variation. For example, the anterior episcleral arterial circle seems to supply four different circulations, and yet all these four areas-episcleral, anterior conjunctival, limbal, and iris-can in their turn receive supplies from other deeper vessels. Leakage began to occur between 4 and 10 seconds after 'first flush' and was confined to conjunctival and episcleral capillaries, but there was minimal masking of detail in the early stages.

There can be little doubt that this advance in fluorescein technique will yield further information as it is more widely practised. The authors are to be congratulated for simplifying anterior segment fluorography and they will be forgiven for showing the circulation to be more complicated than it was previously thought to be. 